Sin:

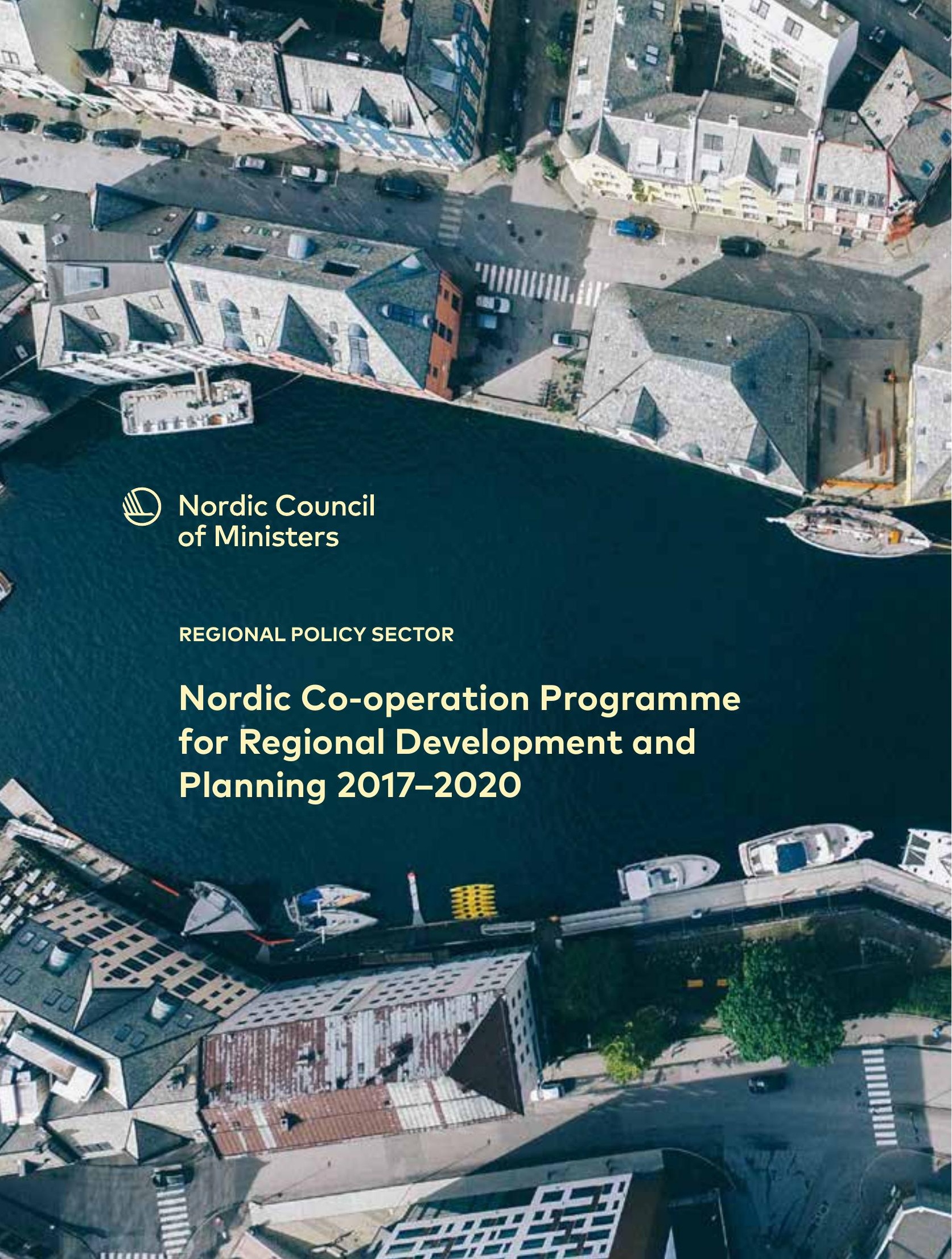




\section{Nordic Co-operation Programme for \\ Regional Development and Planning 2017-2020}

ISBN 978-92-893-4932-1 (PRINT)

ISBN 978-92-893-4933-8 (PDF)

ISBN 978-92-893-4934-5 (EPUB)

http://dx.doi.org/10.6027/ANP2017-723

ANP 2017:723

(C) Nordic Council of Ministers 2017

Layout: Mette Agger Tang

Cover Photo: Unsplash.com

Print: Rosendahls

Printed in Denmark

\section{Nordic co-operation}

Nordic co-operation is one of the world's most extensive forms of regional collaboration, involving Denmark, Finland, Iceland, Norway, Sweden, the Faroe Islands, Greenland, and Åland.

Nordic co-operation has firm traditions in politics, the economy, and culture. It plays an important role in European and international collaboration, and aims at creating a strong Nordic community in a strong Europe.

Nordic co-operation seeks to safeguard Nordic and regional interests and principles in the global community. Shared Nordic values help the region solidify its position as one of the world's most innovative and competitive.

\section{Nordic Council of Ministers \\ Ved Stranden 18 \\ DK-1061 Copenhagen $K$}

www.norden.org

Download other Nordic publications at www.norden.org/nordpub 
REGIONAL POLICY SECTOR

Nordic Co-operation Programme for Regional Development and Planning 2017-2020 


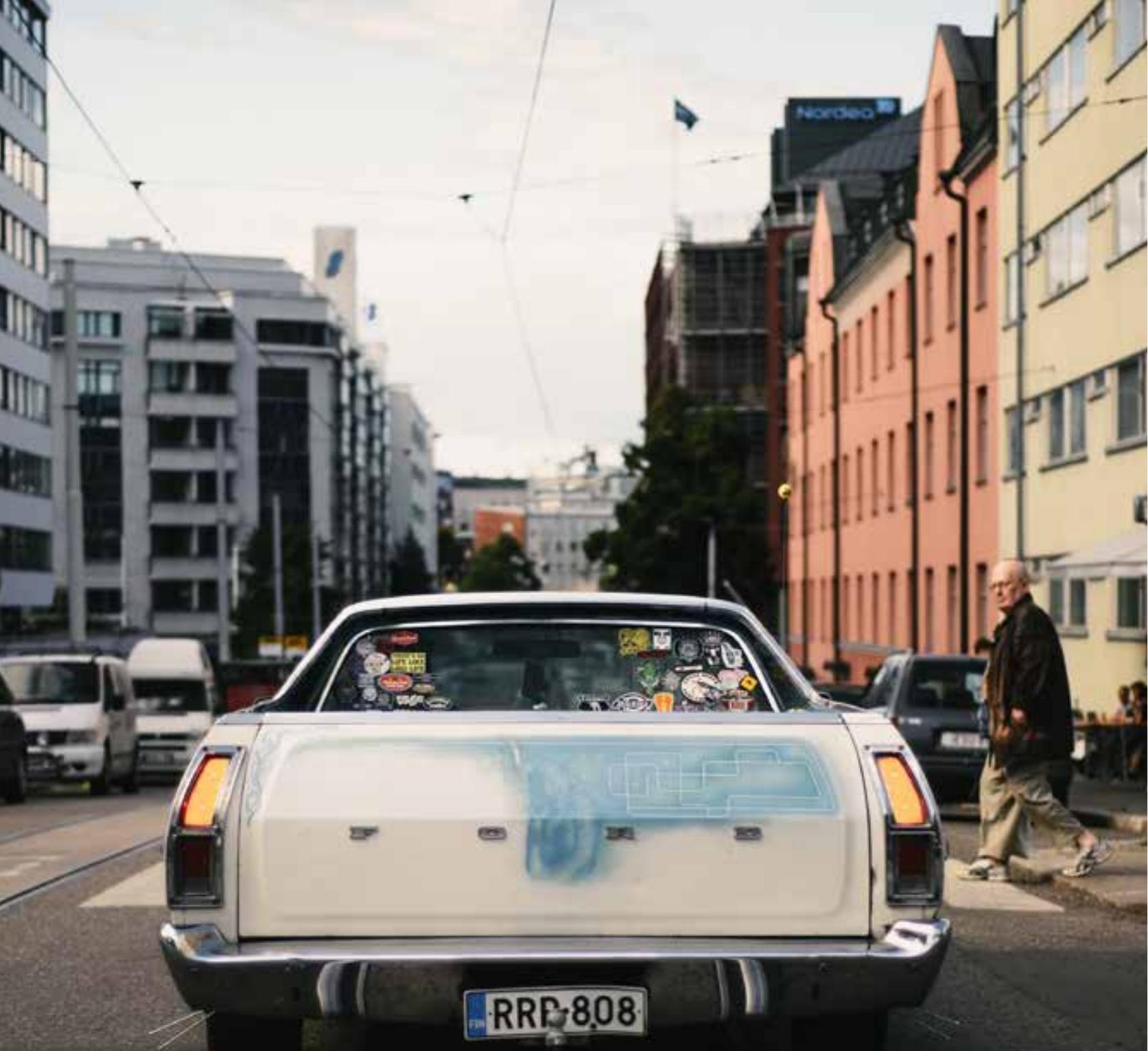




\section{CONTENTS}

\section{Summary}

9 Introduction

About the co-operation programme within the Nordic Council of Ministers About the regional sector's co-operation programme

12 Strategic focus areas and objectives for a cohesive Nordic Region

15 Focus area 1: Sustainable rural development

19 Focus area 2: Innovative and resilient regions

23 Focus area 3: Sustainable cities and urban development

27 Horizontal perspectives

28 Implementation of the co-operation programme Regional policy thematic groups

\section{Organisation of the sector}

The Nordic Council of Ministers for Business, Energy, and Regional Policy (MR-NER)

Nordic Committee of Senior Officials for Regional Policy (EK-R)

Secretariat to the Nordic Council of Ministers

Nordregio - a Nordic knowledge hub on regional development

Cross-border co-operation

West Nordic Fund

A developed sectoral co-ordination of Nordic co-operation 


\section{Summary}

The Nordic ministers for regional affairs hereby present a joint Nordic co-operation programme that aims to lay the foundation for the evolved exchange of knowledge, to provide examples of successful initiatives within priority policy areas, and to strengthen joint efforts relating to regional policy in the Nordic Region.

Nordic co-operation on regional policy has a long history of creating good opportunities for learning, understanding, and joint action. This co-operation is based on the insight that joint learning and solutions are key to achieving results together that contribute to the sustainable development of the individual regions within the Nordic Region as a whole.

The starting point of this co-operation programme is to address the regional policy challenges currently faced by the Nordic Region that it is also likely to face going forwards. An additional starting point of the co-operation programme is the principles of sustainable development and gender equality and the perspectives and rights of children and young people. The Nordic Co-operation Programme for Regional Development and Planning 2017-2020 identifies the topics that the Nordic countries, the Faroe Islands, Greenland, and Åland deem to be the most relevant focus areas. A number of priorities within the context of these focus areas are described in more detail in this co-operation programme.
The choice of focus areas based on a broad consultative process are:

1. Sustainable rural development

2. Innovative and resilient regions

3. Sustainable cities and urban development

The co-operation programme shall help to initiate and implement activities that add value through their implementation at a Nordic rather than a national level. This includes the implementation of projects and studies that contribute to the exchange of knowledge and experience, as well as to policy development. In this way, the programme shall help to improve national and regional policy strategies and initiatives in the field of regional policy. In addition, the cooperation programme shall contribute to the strengthening of co-operation between the sectors and institutions of the Nordic Council of Ministers.

The Nordic Co-operation Programme for Regional Policy for 2017-2020 is to be implemented primarily within the context of three thematic groups that are each - on behalf of the Nordic Committee of Senior Officials for Regional Policy and in close co-operation with Nordregio - responsible for the implementation of the focus areas. In addition, the Nordic institutions within regional policy co-operation assist in the realisation of the programme. 


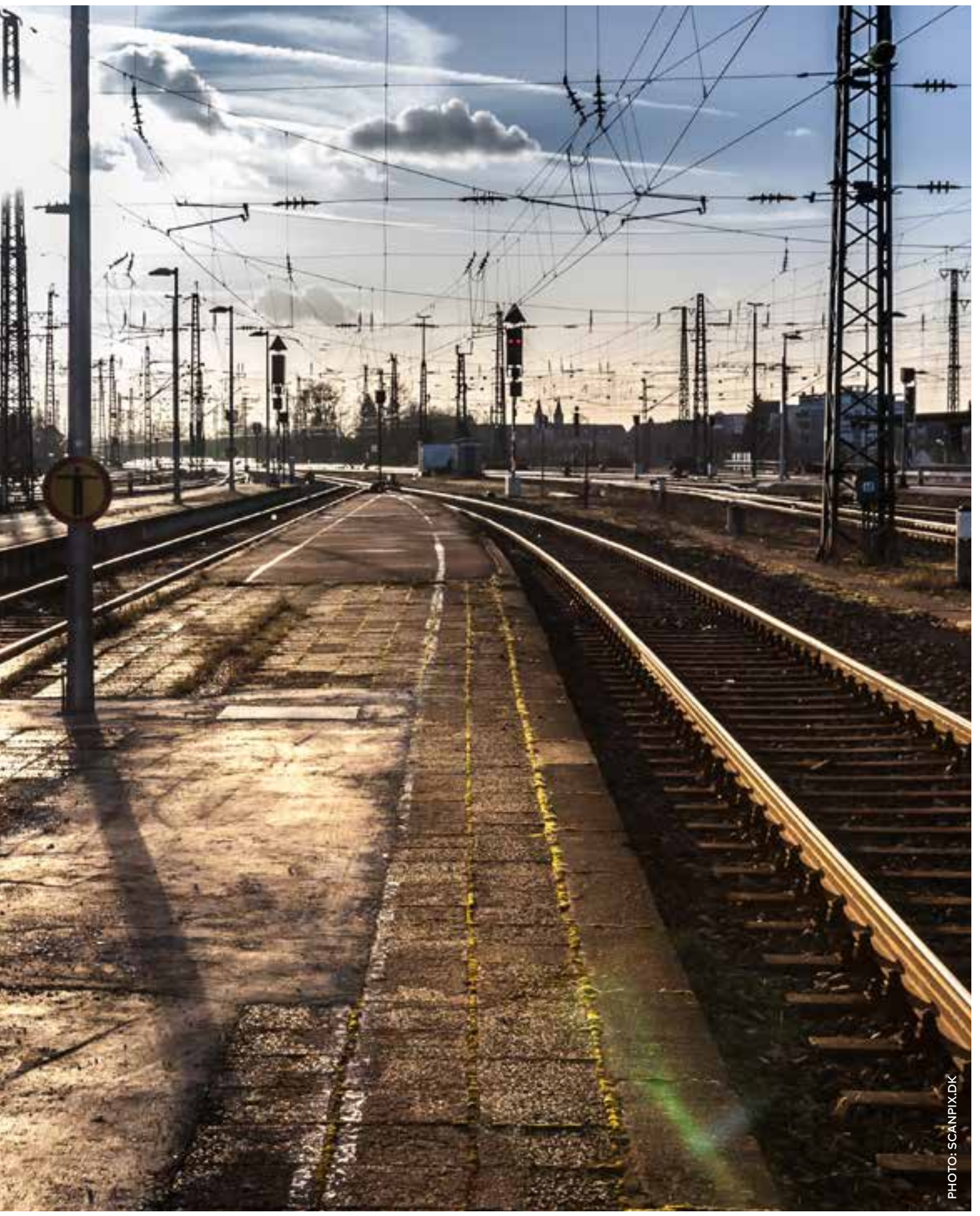




\section{Introduction}

About the co-operation programme within the Nordic Council of Ministers The Nordic Council of Ministers' cooperation programme describes the regional policy sector's policy priorities for the period 2017 to 2020.

The co-operation programme governs the sector's activities, but it shall also be seen in the context of other governing documents in the Nordic Council of Ministers as illustrated in the table below.

About the regional sector's co-operation programme The Nordic ministers for regional affairs hereby present a joint Nordic co-operation programme that aims to provide examples of successful initiatives and new solutions within priority policy areas and to strengthen joint efforts relating to regional policy. The cooperation programme shall contribute to the strengthening of co-operation between the sectors and institutions of the Nordic Council of Ministers.

\section{The Nordic countries have a long history of co-operation on regional policy. This} co-operation is based on the insight that joint learning and solutions are key to achieving results together that contribute to the sustainable development of the individual regions within the Nordic Region as a whole. Nordic co-operation relating to regional development and planning is unique and creates extraordinary opportunities for

\section{GOVERNING DOCUMENTS IN THE NORDIC COUNCIL OF MINISTERS}

Vision statement of the ministers for Nordic co-operation

Target group: Nordic Council of Ministers / Time frame: No end date

Cross-sectoral strategies

Target group: Nordic Council of Ministers / Time frame: Up to six years

\section{Co-operation programmes}

Target group: Sector-specific / Time frame: Four years

Presidency programme

Target group: Nordic Council of Ministers / Time frame: One year 
learning, understanding, and joint efforts in the field of regional policy. At the basis of Nordic co-operation - the Nordic advantage and Nordic added value - are the wide-ranging similarities between the Nordic countries that create the conditions for exchanging knowledge and experience and for learning in the face of similar challenges or problems. Yet there are also differences, such as in planning systems, regional and municipal structures, and the instruments used for regional development, etc., all of which make co-operation dynamic and evolutionary. Nordic co-operation is also a good complement to and platform for national and regional collaboration within Interreg, the Baltic Sea Strategy, VASAB, the Arctic Council, and other international co-operative bodies.

\section{The Nordic Region faces opportunities and challenges in all areas related to sustainable development. In recent} years, economic development has been characterised by economic highs and lows as well as the effects of demographic change by way of rapid urbanisation, an ageing population, and increased refugee immigration. Environmentally, the focus is on achieving global climate goals from 2015 by reducing $\mathrm{CO}_{2}$ emissions and through the transition to a greener economy. Most of the Nordic countries are developing or implementing strategies for the transition to green growth and a bioeconomy, which in turn is important for regional development. Historically, it has been important to promote social sustainability within Nordic cooperation. Today, the social dimension of regional development is accentuated by refugee flows and the role of the regions in receiving and integrating their newly arrived residents. The UN is in the process of drafting Agenda 2030, which will be a key strategy and set important objectives for the regional sector to relate and contribute to.

\section{Nordic co-operation on regional policy has promoted the exchange of know- ledge and experience between the} Nordic countries, the Faroe Islands, Greenland, and Åland by, for instance, conducting projects and exchanging experience within the context of thematic working groups, and by establishing joint statistical databases as a basis for comparative analyses in the Nordic Region and in relation to the rest of Europe. In addition, joint research has long been conducted (within the Nordregio research institute) to increase knowledge about the conditions for regional development and planning and about the effects of policy measures in the Nordic regions. The Nordic countries have also increased their knowledge base relative to measures within the EU's cohesion policy, not least through active participation in national, regional, border-region, and transnational programmes, as well as through the EU Strategy for the Baltic Sea Region. 
Co-operation between border regions has been important for Nordic co-operation as a whole. The basis for co-operation between border regions has been that these regions are often peripheral in their respective countries and therefore have much to gain by working together across national borders, while the borders themselves present barriers to the freedom of movement of businesses and workers. Many solutions for services, commuting, business development, and reduced barriers to freedom of movement across border regions have been developed within the context of Nordic co-operation, such as through Nordic cross-border co-operation committees and with the support of programmes such as the Nordic Arctic Co-operation Programme, the Nordic Demography Programme, and the EU Interreg programmes.

The starting point of the Nordic cooperation programme for regional policy is to address some of the challenges currently faced by the Nordic Region that it is also likely to face going forwards. All the Nordic countries have the overall national objective of achieving sustainable regional growth or development by maximising the potential of all parts of the country, from cities to rural areas. Nordic co-operation on regional policy and regional planning is based on these overall national objectives and has identified three broad focus areas that the countries together deem to be most important for achieving these long-term objectives (see page 12).

The Nordic Council of Ministers for Business, Energy, and Regional Policy (MR-NER) adopted the co-operation programme in the autumn of 2016. The programme will run until 2020. Knowledge and experience from the implementation of the previous co-operation programme have been drawn on in the development of the co-operation programme for 2017 to 2020. 


\section{Strategic focus areas and objectives for a cohesive Nordic Region}

The strategic focus areas described in this programme build on the previous areas for Nordic regional policy collaboration, knowledge-building, exchange of experience, and policy development, as well as on co-operation between border regions in the Nordic countries, the Faroe Islands, Greenland, and Åland.

The challenges to regional policy that the Nordic countries consider most relevant to the co-operation programme for 2017-2020 can be summarised in three focus areas. The choice of focus areas is based on a review of the Nordic countries' priorities for regional policy to 2020 as well as on a broad consultative process in all the Nordic countries, the Faroe Islands, Greenland, and Åland. These are:

\section{Sustainable rural development \\ 2. Innovative and resilient regions \\ 3. Sustainable cities and urban development}

As part of the Nordic co-operation programme for regional development and planning 2017-2020, projects and activities are prioritised that aim to identify, analyse, compare, and develop Nordic examples of and solutions to regional and local challenges related to sustainable rural development, innovative and resilient regions, and sustainable cities and urban development.

In developing projects, the horizontal perspectives and cross-sectoral collaboration presented below must be taken into account (see pages 27 and 34).

A thematic group will be established for each focus area (see page 28). Each thematic group is tasked with drawing up a work programme for each focus area, establishing the objectives, activities, schedule, and budget for the implementation of the focus area.

\section{Strategic objectives and expected} impact of the co-operation programme The Nordic co-operation programme for regional development and planning shall help to initiate and implement activities that add value through their implementation at a Nordic rather than a national level. This includes the implementation of projects and studies that contribute to the development of knowledge and policies and thus contribute to the improvement of national and regional policy strategies and instruments, including crosssectoral areas (see page 27). This programme accentuates the regional dimension and a desire to implement more of the co-operation programme in collaboration with the regions, 
regional co-operative bodies, and national authorities in regional policy, as well as between sectors that have an influence on regional development. In this way, a strategic objective of the programme is to strengthen cooperation between the national and regional levels in all the Nordic countries, the Faroe Islands, Greenland, and Alland to create synergies in regional development efforts and to contribute to the development of regional strategies.

In addition, the co-operation programme shall contribute to the strengthening of co-operation between
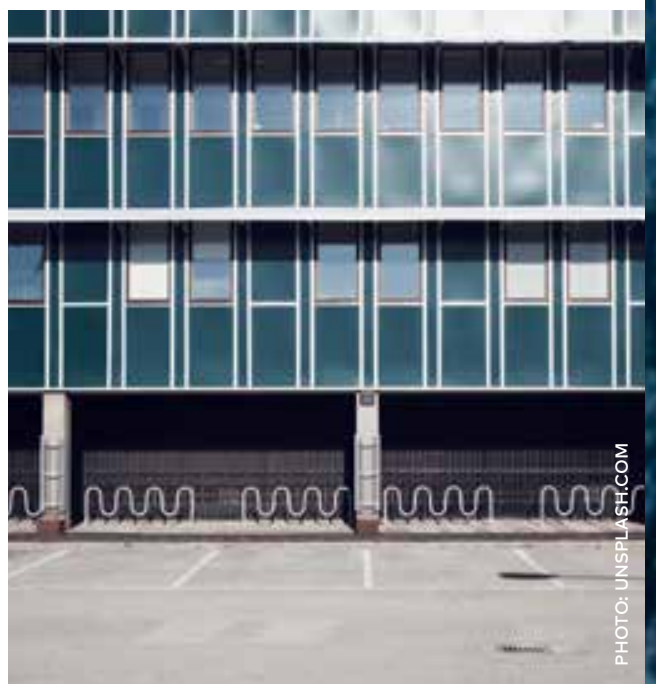

the sectors and institutions of the Nordic Council of Ministers. A strategic objective for the implementation of the programme is the improvement of interaction between other Nordic programmes and strategies (e.g. the transfer of knowledge from the Arctic Co-operation Programme). The programme shall also make a concrete and relevant contribution to the work of the Nordic countries and regions within the context of European programmes, strategies, and funds.

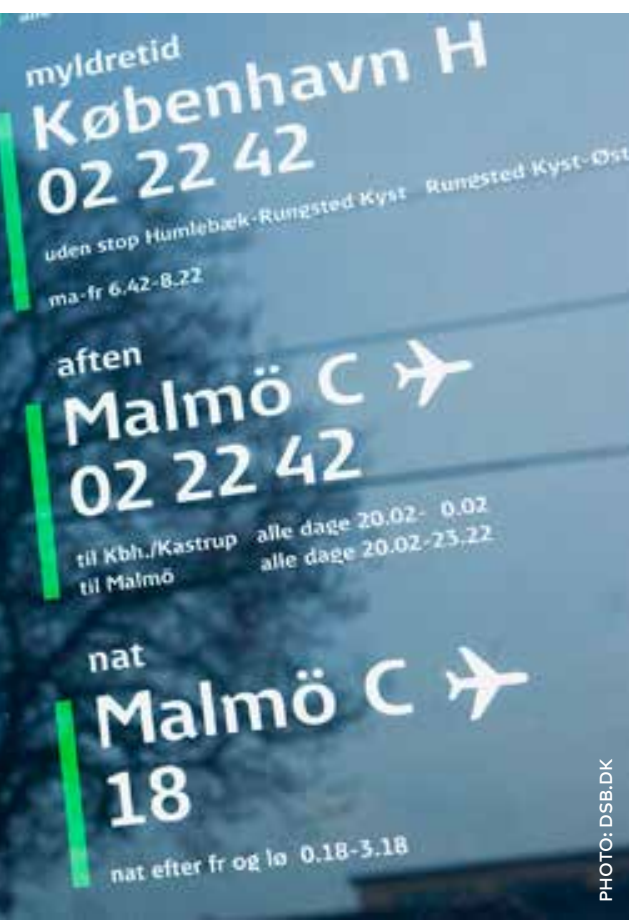



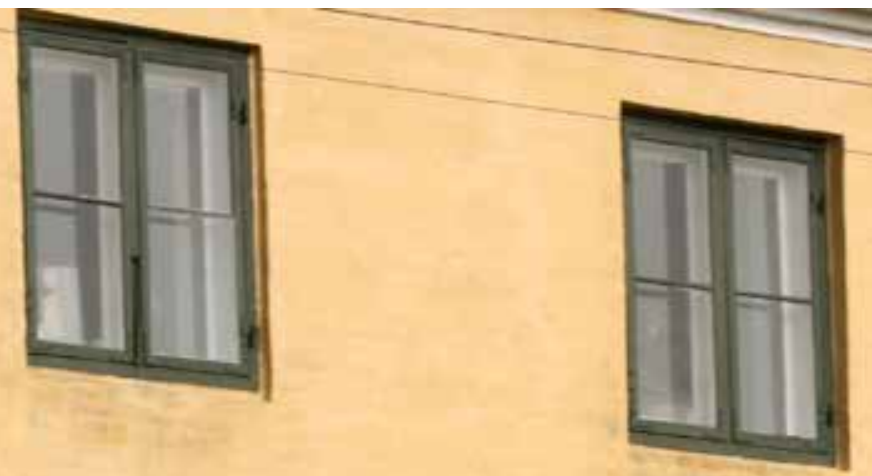

Ant

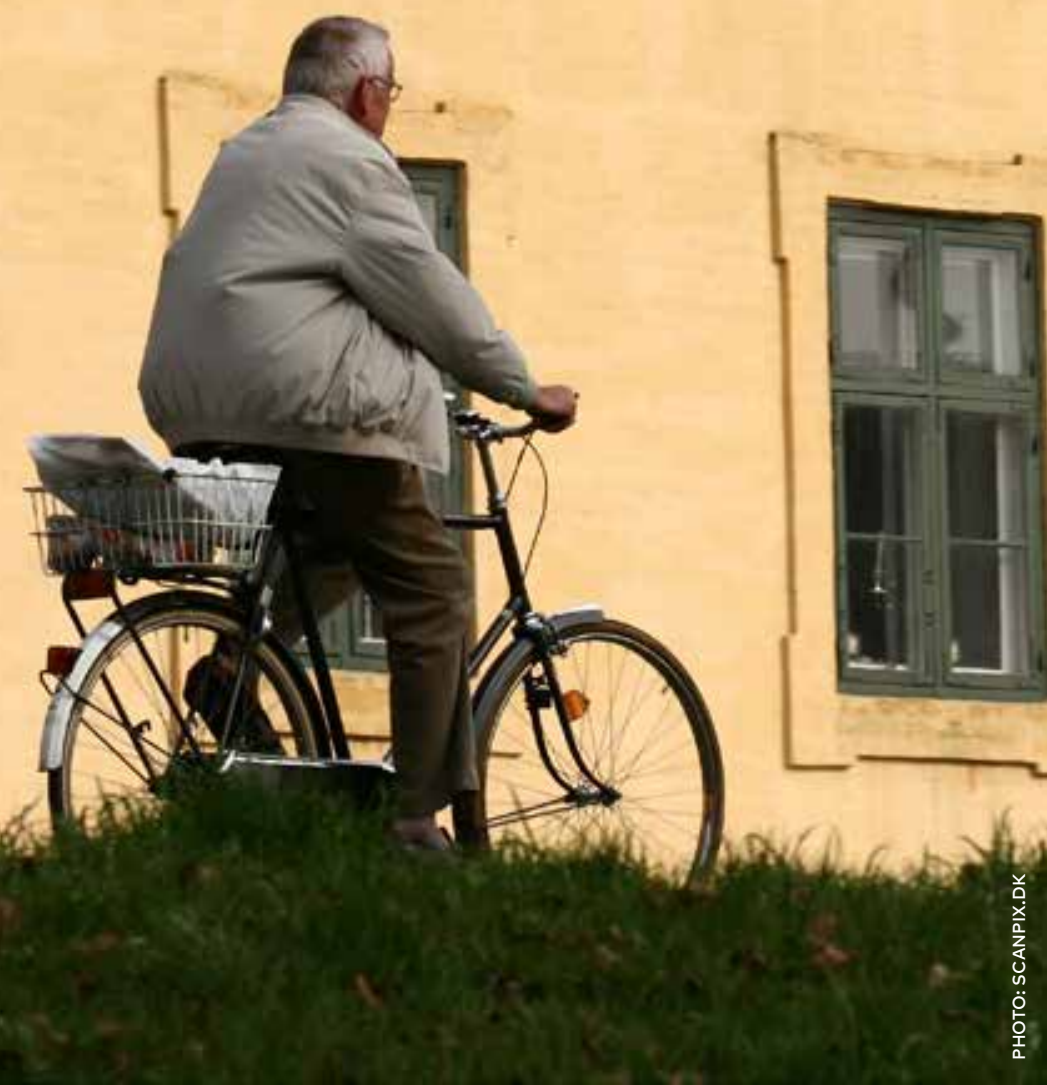




\section{Focus area 1: \\ Sustainable rural development}

Rural development is an important theme in all the Nordic countries, the Faroe Islands, Greenland, and Åland. All geographic areas are affected by a number of challenges such as demographics, services, infrastructure, digitalisation, industry, housing, attractiveness, education and employment, nature, and the environment. The development of rural, sparsely-populated, and peripheral areas is important for the cohesive development of the Nordic Region as a whole. This is to take advantage of the potential of the Nordic regions and thereby help to counter the growing regional imbalance in terms of economic growth, population growth, access to services, gender equality, and education.

The different conditions for regional development described above are based on a number of trends affecting all the Nordic countries - primarily globalisation and urbanisation, or the centralisation of populations from the periphery and sparsely-populated areas to regional centres and metropolitan regions. The State of the Nordic Region report states that the 30 biggest urban regions in the Nordic Region have absorbed more than 97 per cent of its population growth in the last 20 years. International migration accounts for two-thirds of the total population increase. The consequence for the other regions that have little or negative population growth is a growing labour shortage as there are fewer people of working age to support a growing number of elderly people. Rural development capabilities also vary widely depending on population sparsity and distance to major cities and markets.

\section{PRIORITIES WITHIN THE CONTEXT OF} THE CO-OPERATION PROGRAMME

\section{Ageing populations challenge welfare systems - demographic challenge} The whole of the Nordic Region is facing a huge increase in the number of people aged 65 and over. Over the next 30 years the Nordic Region will experience an increase in this age group of between 50 and 100 per cent. The ageing population and urbanisation pose especially great challenges to many of the Nordic Region's peripheral and sparsely populated regions. This is also clear from the demographic vulnerability index created by Nordregio within the context of the Nordic co-operation programme for the regional sector for 2009-2012. The combination of a declining share of the population of working age and an increasing share of the population in need of care poses both economic and personnel challenges in terms of providing services and welfare. There is a need to develop structural solutions in relation to how the labour market 
operates, e.g. to encourage more men to work in the welfare sector, and to encourage more people to work longer by raising the age of retirement and through work environment initiatives etc. However, there is also a need for innovative service solutions and models to address demographic challenges based on the differing conditions of regions and communities.

\section{Social innovation and social entrepreneurship - new ways to deliver services}

Against this background, the potential for social innovation and social entrepreneurship (i.e. new ways of delivering welfare services) has been the subject of increasing political attention in recent years. Social entrepreneurship and social innovation mean developing new service solutions while creating new social relations in order to strengthen the local community and social capital. The wealth generated from and sustainability of social innovation depend on a number of factors, such as procurement rules and funding opportunities, as well as the existence of institutions responsible for promoting innovation (funds, government agencies, intermediary institutions, etc.). Areas where there are already examples of how social innovation contributes to the development of local communities in the Nordic countries include health, education, the labour market, and social care. Within these areas there are further opportunities for joint learning and development at the national and regional levels.

The supply of skills is a growing challenge for the Nordic regions, a challenge which is also addressed in focus area 2. Demographic changes mean that this challenge is especially prominent in rural regions. Increasing immigration to the Nordic Region does, however, have a more positive effect on population growth even in the more peripheral regions. The key to sustainable population growth in these regions is stimulating inward migration and encouraging people to remain by offering good conditions for the inclusion of new residents in local labour markets. There is scope for the exchange of experience and the development of new initiatives for the validation of skills, adult education, language training, entrepreneurship, etc.

\section{Peripheral regions will be strengthened} through co-operation between border regions and by increasing accessibility In the most peripheral and sparsely populated Nordic regions the biggest challenges generally relate to demographics, services, infrastructure, and the labour market. Co-operation between border regions can help to solve these challenges. Nordic co-operation in these areas is also touched upon in focus area 2 below. Another important prerequisite for sustainable regional development is increased accessibility, both physical and digital. 


\section{GOALS/OBJECTIVES OF ACTIVITIES IN FOCUS AREA 1}

The goals for this focus area are to contribute to the development of policies and new solutions to the challenges that the countries face with regard to sustainable rural development. Projects and activities must:

- Contribute to the continued development of knowledge by identifying specific examples, statistics, and policy-relevant conclusions.

- Identify organisational and structural aspects of the implementation of regional policy and contribute to an understanding of how multi-level governance affects the implementation of policies and initiatives in the focus area.

The expected results are that the initiatives and activities that seek to fulfil the objectives will be implemented within each priority area; i.e.: demographic challenges, social innovation and entrepreneurship in services, skills supply, and co-operation between border regions. These initiatives and activities shall demonstrate concrete results and lessons that Nordic stakeholders can leverage in their policy development. The focus of these initiatives and activities and their specific objectives shall be developed and clarified within the context of the thematic group's programme.

Target groups are national, regional, and local authorities, as well as stakeholders and organisations involved in regional policy and rural development in the Nordic countries. The effective transfer of knowledge shall be ensured by way of a clear formulation of the target group in the thematic group's work programme, a clear communication plan, and regular dialogue between the thematic group and the target groups. 


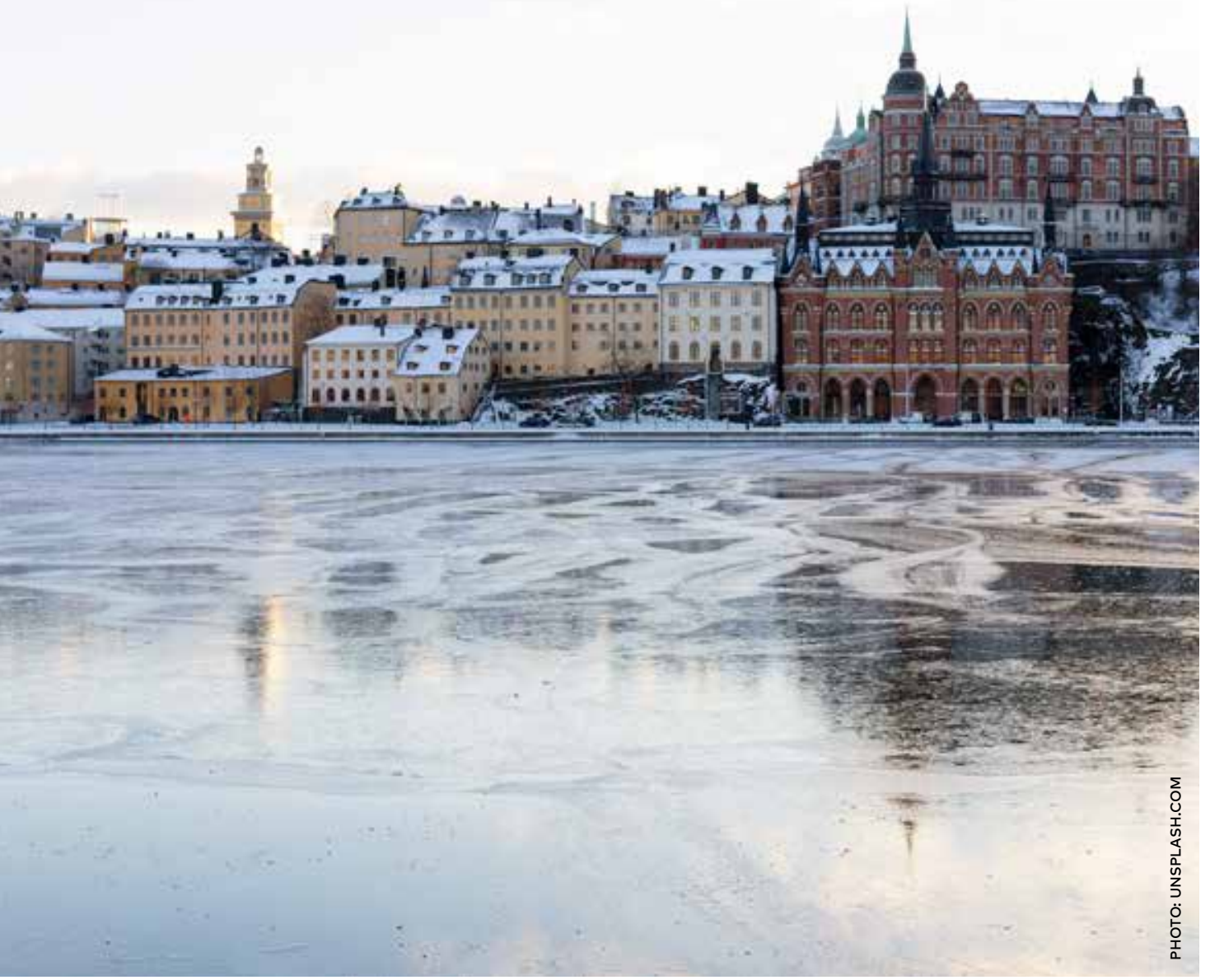




\section{Focus area 2: Innovative and resilient regions}

The economic growth of the Nordic Region is created regionally and locally through innovation and entrepreneurship. It is important that regional policy supports and stimulates regional innovation environments and business promotion measures so that the regions can take advantage of their development potential for smart and sustainable development. This involves establishing and developing strategic partnerships between research bodies, public authorities, and businesses in urban and rural areas with a view to achieving sustainable development. Cluster development and regional innovation processes are interesting topics to expand on, as are understanding and building on the opportunities and challenges presented by globalisation.

The analysis of innovation and research environments in the Nordic Region is today closely linked to the concept of smart specialisation, which is widely applied throughout Europe. The Nordic regions should use this mindset to create their own innovation strategies and to develop innovative regional environments based on their existing strengths by combining resources in new ways that involve new stakeholders in their efforts.

For Nordic regions that are part of open global economies but also base much of their sustainable growth on local commodities and resources, it is extremely important to understand the local and global relationships, such as within the bioeconomy and bio-based products. It is also important to analyse successful examples and opportunities to further develop innovative regional environments (clusters, centres of excellence, etc.) not just in major cities but also in the more peripheral regions such as in the Arctic.

\section{PRIORITIES WITHIN THE CONTEXT OF THE CO-OPERATION PROGRAMME}

Green growth, blue growth, bioeconomy, smart energy systems

An overarching goal of European and Nordic co-operation is the transition to smart, sustainable, green growth that takes into account both social and environmental challenges, including the climate and global warming. Investments and innovations that contribute to sustainable development should be supported and encouraged. Of particular concern in the Nordic Region is the promotion of green industries and circular business models, the blue bioeconomy, and sustainable energy production in smart energy systems. The Nordic Council of Ministers has taken a long-term approach to these issues over a long time period, not least as a horizontal action leader for the bioeconomy within the context of the EU Strategy for the Baltic Sea Region. 
Several of the Nordic countries have national strategies for regional development that include clear components of green growth and the bioeconomy, linked to green business development and innovation. Several of the countries have also promoted green growth and the bioeconomy/blue bioeconomy in their most recent Nordic presidency programmes, such as Iceland (with NordBio), and Denmark and Finland (blue bioeconomy). The Arctic has also been a focus here, not least in the context of NordBio and the Arctic bioeconomy programme.

The conditions for green growth and for achieving environmental and climate goals vary widely between the different regions. The regional sector will therefore seek to identify the potential for green growth in the various regions, as well as how the regions can help the Nordic Region to achieve global climate and environmental goals. The continued development of the Nordic countries' regional strategies and innovation environments will play a key role in promoting and leveraging the potential for green growth, including growth of the bioeconomy.

\section{Supply of skills and capital}

With regard to local and regional labour markets, the supply of skills is one of the most important issues for the development of the Nordic regions. This is important both for maintaining and developing existing businesses, and for establishing new businesses in areas such as digitalisation and green growth.
The matching and integration of immigrants in the labour market is also important, as are flexible systems for lifelong learning.

Regional educational institutions are an important source of development for local/regional innovation environments. But even if there are successful and innovative ideas, access to venture capital is often a limiting factor, especially in sparsely populated regions. Consequently, a key regional challenge is to create the conditions needed for increased growth by increasing cooperation between research and innovation environments, private and public enterprises, and venture capital companies.

\section{Regional strategies}

\section{for sustainable growth}

More efficient links between national and regional strategies and the local level have been discussed extensively as part of regional policy in the Nordic countries. A regional development strategy aims to develop the region based on comparative advantages/strengths. An important dimension is, as mentioned earlier, the concept of smart specialisation as promoted by the EU. There is currently no overview of how the Nordic regions adapt to and apply this kind of concept to their strategies nor how they are monitored and evaluated. Consequently, there is huge potential for joint Nordic learning and comparisons in this area.

One ambition is to focus in particular on our Arctic regions in order to link with 
previous initiatives for developing local strategies for smart specialisation in some Arctic communities, and to link with the forecasts for opportunities and challenges related to sustainable regional development in the Arctic that were developed within the context of the previous regional policy co-operation programme.

\section{GOALS/OBJECTIVES OF ACTIVITIES IN FOCUS AREA 2}

The goals for this focus area are to contribute to the development of policies and new solutions to the challenges that the countries face in relation to innovative and resilient regions. Projects and activities must:

- Provide concrete lessons, examples, statistics, and policy-relevant conclusions to stimulate and develop innovative regional economies at all policy levels, not least in the areas of the green and blue economy.

- Support and stimulate regional stakeholders so that they can leverage their innovation and development potential.

- Promote and analyse the challenges and obstacles that the Nordic countries and regions face in relation to promoting innovative and resilient regions, green growth, and smart specialisation, and provide examples of strategies or solutions to the greatest extent possible.

The expected results are that initiatives will be implemented in each priority area on the basis of the above objectives; i.e.: green growth, blue growth, bioeconomy, smart energy systems, supply of skills and capital, and regional strategies for sustainable growth. These initiatives and activities shall demonstrate concrete results and lessons that Nordic stakeholders can leverage in their policy development. The focus of these initiatives and their specific objectives shall be developed and clarified within the context of the thematic group's programme.

Target groups are national, regional, and local authorities, as well as stakeholders and organisations involved in regional policy, innovation, and business development in the Nordic countries. The effective transfer of knowledge shall be ensured by way of a clear formulation of the target group in the thematic group's work programme, a clear communication plan, and regular dialogue between the thematic group and the target groups. 


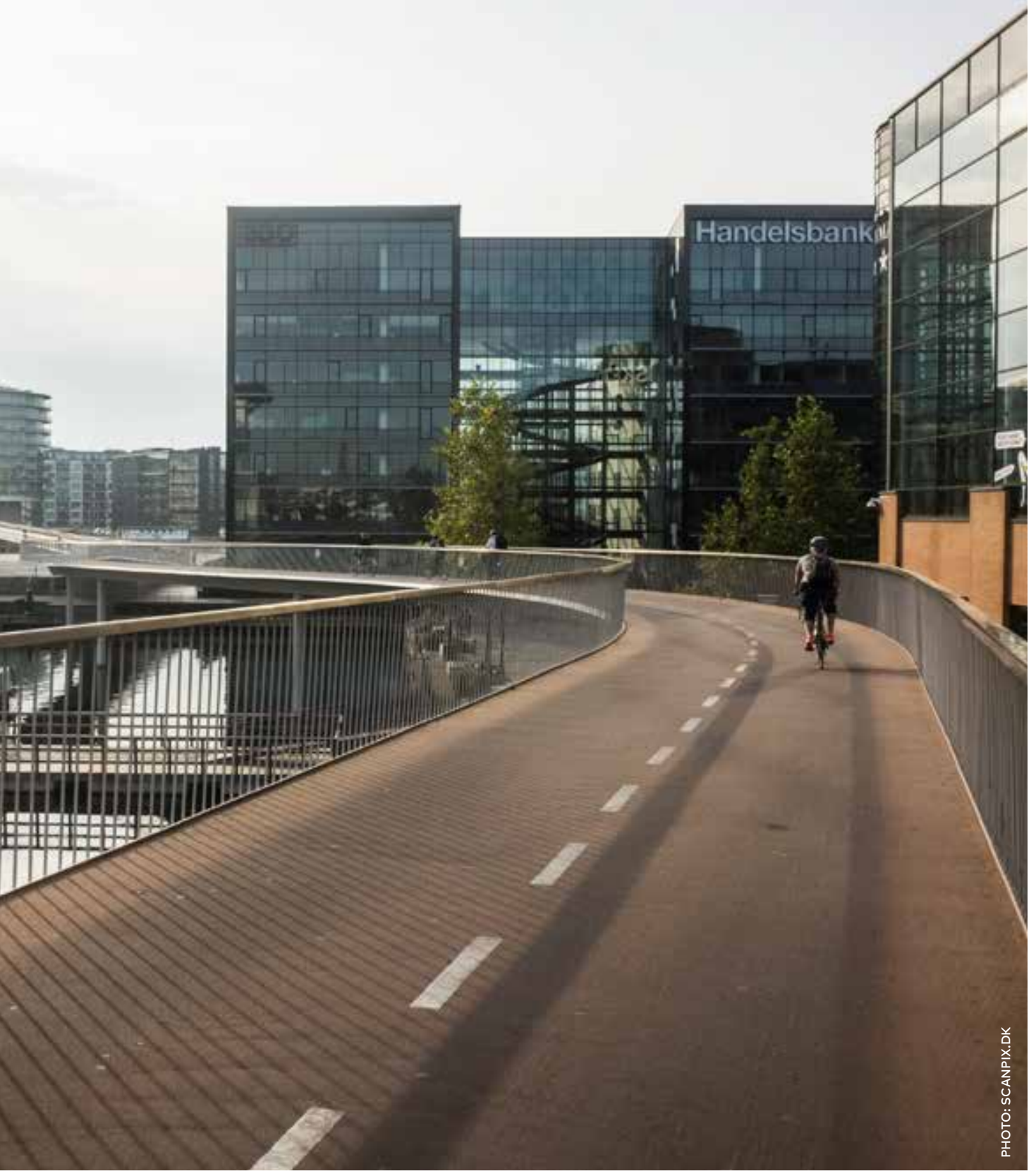




\section{Focus area 3: Sustainable cities and urban development}

Making cities less vulnerable and switching to environmentally friendly transport systems and local energy solutions are key development issues for all Nordic regions and for the sustainable development of major cities. In this regional policy focus area, issues related to housing, transport, and energy systems/ climate adaptation are of the highest priority. The Nordic countries, the Faroe Islands, Greenland, and Åland largely share the challenges posed by the effect of urbanisation and centralisation on cities, whether large metropolises or small or medium-sized towns. The challenges relate to smart growth and not creating cities that have a large environmental burden, to countering segregation, creating attractive and inclusive environments, leveraging the potential of digitalisation in the development of smart cities, and overcoming the divisions between cities and the surrounding countryside. It is important that Nordic cities are attractive, function effectively, and are safe for everyone. Historically, the Nordic countries have had a similar pattern of urban development and have similarities in their planning and management. Yet there are also sufficient key differences both between and within the countries for lessons to be learned with regard to urban regional development. The "Nordic Built Cities" initiative focuses on sustainable construction, architecture, and urban development and so is relevant to this focus area, not least in terms of the ex-port of ideas and concepts that can be further developed in the context of planning and sustainable urban development.

\section{PRIORITIES WITHIN THE CONTEXT OF THE CO-OPERATION PROGRAMME}

Social sustainability and gender equality Social sustainability and migration are two of the foremost challenges to creating attractive and sustainable cities in the Nordic Region. Social cohesion and the social contract are strong international competitive advantages for the Nordic Region, but they are currently being challenged by increased segregation and major socioeconomic disparities, not least in the urban areas. The consequences of migration to cities in terms of segregation, housing, and localisation are important issues in the study and development of action plans and measures linked to such aspects as quality of life, public health, and rights to the city and public space. In particular, the concepts of social sustainability and gender equality should be investigated as part of urban planning and in issues related to new forms of participation in the planning and design of cities, not least in the context of a more multi-cultural Nordic Region. 


\section{Spatial planning}

The tension between legitimacy and effectiveness, and between democratically well-anchored planning processes and economically rational processes poses a major challenge to all of the Nordic regions. Many areas have housing shortages and face major environmental challenges, while planning issues are often widespread. In other places, the challenge is how to plan within sparse structures and address issues such as empty buildings. An interesting question in a Nordic context is the importance of technology for development, such as the potential linked to the digitalisation of planning processes, the use of social media and "big data" in spatial planning, and the challenges these may pose.

Relations between regionally strategic development efforts and municipal comprehensive planning is another related issue that is of particular importance in this context, not least in relation to the horizontal perspectives mentioned in "Horizontal Perspectives", which looks at ongoing municipal and regional reforms.

\section{Urban qualities in small and medium-sized towns, and the urban-rural relationship}

The prevailing ideal of compact urban environments with urban qualities is not limited to the major cities but forms the basis for small and medium-sized towns as well. Interesting practical as well as knowledge-based challenges include how we can work with urban policy to develop attractive urban environments in small and medium-sized towns. Compact urban environments enable the development of environmentally friendly transport systems and local energy solutions, which are an interesting topic for further investigation in this focus area. The urban-rural relationship, as well as the relationship between sparsely populated and densely populated areas, is changing by way of urbanisation. Technological developments coupled with cultural and economic globalisation also make these relationships increasingly complex. In this context we also need to ask fundamental questions about how urban and rural environments relate to each other in different types of functional urban regions, and how places interact and influence each other in order to be able to build smart and enjoy effective co-operation going forwards.

\section{The growth and development of}

\section{Arctic cities and towns}

A key focus area for further work on urban sustainability is the growing towns of the Arctic regions. Many cities and towns in the Arctic are undergoing huge transformation and represent good examples of urban transformation and interesting processes in urban development. 


\section{GOALS/OBJECTIVES OF ACTIVITIES IN FOCUS AREA 3}

The goals for this focus area are to contribute to the development of policies and propose new solutions to the challenges that the countries face with regard to sustainable urban development. Projects and activities must:

- Provide concrete lessons and solutions to the problems that the countries face in their urban development and in the interaction between cities and other parts of metropolitan areas, regions, and countries.

- Help to clarify and streamline the relationships between regional strategic development and municipal comprehensive plans.

- Stimulate exchanges and learning between the Nordic regions and cities in terms of concrete actions and policies for sustainable urban development to address segregation and housing, the climate, environment and energy systems, improved quality of life and public health, right to the city and public space, as well as participation in planning.

The expected results are that initiatives will be implemented in each priority area on the basis of the above objectives; i.e.: social sustainability and gender equality, spatial planning, urban qualities in small and medium-sized towns, and the growth and development of Arctic towns. These initiatives shall demonstrate concrete results and lessons that Nordic stakeholders can leverage in their planning and policy development. The focus of these initiatives and their specific objectives shall be developed and clarified within the context of the thematic group's programme.

Target groups are central, regional, and local authorities, as well as stakeholders and organisations involved in regional policy and sustainable urban development in the Nordic countries. The effective transfer of knowledge shall be ensured by way of a clear formulation of the target group in the thematic group's work programme, a clear communication plan, and regular dialogue between the thematic group and the target groups. 


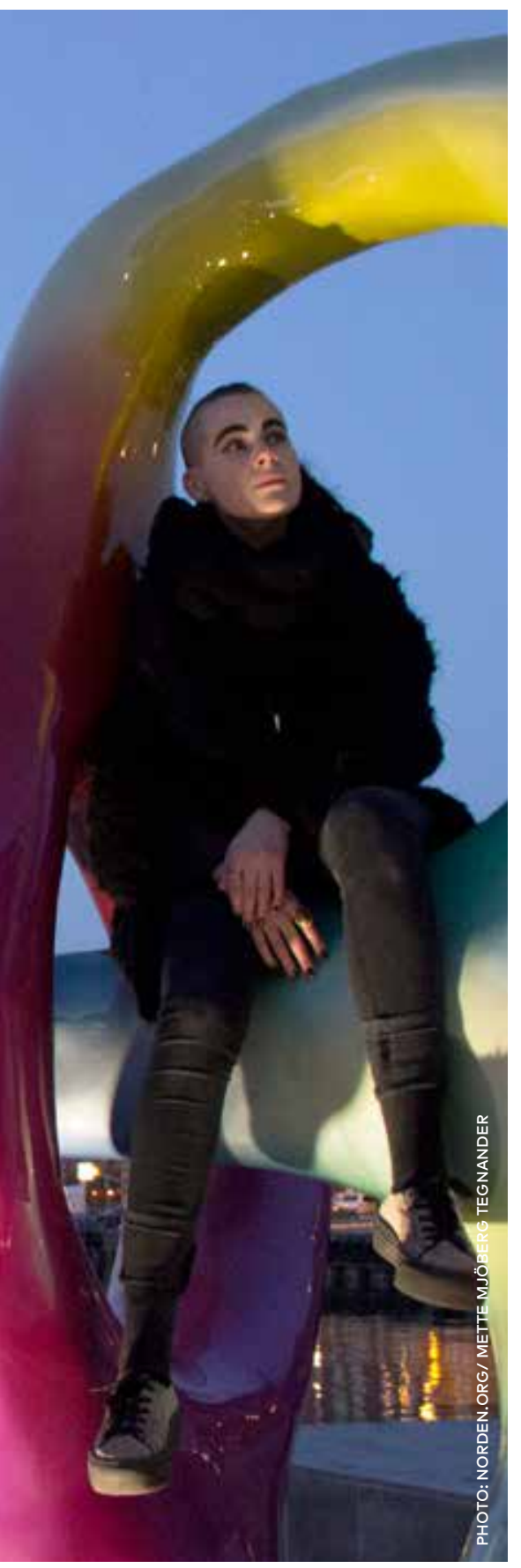




\section{Horizontal perspectives}

\section{Gender equality, sustainable develop- ment, and the inclusion and participa- tion of children and young people are} key aspects of the Nordic brand, and the Nordic Region often positions itself as a pioneer in these areas. In its strategic documents such as $A$ good life in a sustainable Nordic Region and Children and young people - a cross-sectoral strategy for the Nordic Council of Ministers 2016-2022, the Nordic Council of Ministers promotes two cross-sectoral topics that must also be considered in this co-operation programme. These are the conditions and opportunities for children and young people, and economic, social, and environmental sustainability (here the Nordic GRO portal serves as a process tool for projects in the co-operation programme). The gender equality perspective must be integrated in all activities. Specifically this means that all of these aspects are included in the implementation of this co-operation programme.

Integration and demographic development are now fundamental conditions for the Nordic Region's regional development and should be considered in all three focus areas. Demographic challenges have an effect on the prospects for rural development, the regions' "smart" strategies and skills supply, and urban growth and planning conditions. These too should be taken into account the Nordic cross-sectoral initiatives developed to promote developed integration.

Regions in the Nordic Arctic often have special conditions and challenges in the focus areas covered by this co-operation programme. The thematic issues are often the same as for other regions in the Nordic Region, but they are affected and accentuated by the climate, sparsely populated areas, distance, culture, and land conflicts that characterise the Arctic. It is important that all focus areas include and relate to the Arctic regions and their development in the projects and activities undertaken.

Municipal and regional reforms, mergers, new forms of governance and organisation, divisions of responsibility, cityregional co-operation, etc. are enduringly relevant issues in the Nordic countries. Municipal and regional reforms are not unproblematic to implement, and there is much to gain from the exchange of experience between the Nordic countries and regions that are in different stages of the reform process. 
implement the co-operation programme are linked to the focus areas presented. Knowledge and experience of previous working groups within Nordic cooperation on regional policy shall be leveraged in the work of the thematic groups. Thematic groups are established within the following focus areas:

1. Sustainable rural development

2. Innovative and resilient regions

3. Sustainable cities and urban development

The purpose of the thematic groups is to bring together relevant and interested stakeholders at the national and regional level in the Nordic countries within each focus area. An important prerequisite for the thematic groups is that their activities are established and prioritised in all the Nordic countries where their activities are being implemented. This is primarily a responsibility of the representatives of the Nordic ministries. The composition and direction of the thematic groups may depend on the focus areas being different for each of the thematic groups. Co-operation between the Nordic countries and various stakeholders may vary between the thematic groups. Furthermore, it is important that initiatives implemented are for the benefit of all the Nordic countries, the Faroe Islands, Greenland, and Åland

The thematic groups are led by representatives of the Nordic countries, who undertake to lead and co-ordinate the work of the thematic group in collaboration with other participating countries and stakeholders. Experience from the previous co-operation programme shows that it is essential that all the Nordic countries participate in all the thematic groups. In light of the ambition for the thematic groups' activities to provide a Nordic advantage and added value and to reflect policy-relevant regional policy issues, there should be the ambition that the focus areas and thematic groups generate an interest from all countries.

Based on the experience of the previous co-operation programme, it is essential that regional stakeholders are clearly involved in the implementation of the co-operation programme at an early stage.

In addition to directly affected representatives for the Nordic countries and regions, other relevant stakeholders should be involved in the activities of the thematic groups in order to provide knowledge, networks, and analyses. These include research institutes and other academic environments, consultants, and/or other knowledge-supporting organisations in the Nordic Region.

Other stakeholders who should be involved, not least to disseminate knowledge and experience that can contribute to learning, are Nordic national authorities with responsibilities in each area. This would also help to disseminate 
knowledge and awareness of the activities at a Nordic level within the field of regional policy. This may be achieved through the use of reference groups on various initiatives, or by involving these stakeholders in policy analysis or policy recommendations.

In order to create opportunities for following up and evaluating the thematic groups' activities and to help to implement the focus areas and Nordic regional policy objectives for 2017-2020, initially a work programme for each thematic group and focus area will be drawn up. The work programme shall specify the objectives for the focus areas and thus contribute to a clearer prioritisation of initiatives and activities within the context of each focus area.

The work programme shall include a budget, schedule, and activities on a year-by-year basis for the thematic group's activities. The work programme should also clarify and describe how co-operation with e.g. NORA, the cross-border co-operation committees, other regional stakeholders, and national authorities shall be developed. The work programme shall be drawn up under the supervision of the thematic group's chairperson when the thematic group's work starts. It shall be anchored in and adopted by EK-R following its presentation and discussion at a meeting of the committee of senior officials. The chairperson of the thematic group shall submit an annual report describing the progress of the group's efforts to the
Nordic ministers for regional affairs, and propose at least one area which can be discussed in greater detail at a ministerial meeting. Such a discussion shall in turn be based on documents prepared within the context of the thematic group's activities.

Nordregio plays a central role in supporting the thematic groups' work during the programme period by way of established secretariat support and targeted strategic knowledge support. This is in turn based on a clear anchoring and division of responsibilities in the organisation, as well as on the assurance that co-operation between the thematic groups is ongoing. In close co-operation with the relevant ministries and regional stakeholders, Nordregio also has primary responsibility for the communication and the dissemination of knowledge and results developed by the thematic groups.

In order to enable the co-operation programme to contribute to the Nordic countries' work as part of EU cooperation, a working group for EU coordination is also established. This working group should build on the EU network that was active during the previous co-operation programme. The task of this working group is to promote learning and the exchange of knowledge on EU issues, and to promote Nordic participation in European programmes, strategies, and funds, such as the EU Strategy for the Baltic Sea Region, Interreg, EU structural funds, etc. 


\section{Organisation of the sector}

Nordic co-operation on regional policy is composed of the Nordic Council of Ministers for Business, Energy, and Regional Policy (MR-NER), the Nordic Committee of Senior Officials for Regional Policy (EK$R$ ), the secretariat to the Nordic Council of Ministers, Nordregio, as well as cross-border co-operation through the cross-border co-operation committees, NORA, and the West Nordic Fund.

The Nordic Council of Ministers for Business, Energy, and Regional Policy (MR-NER)

The Nordic Council of Ministers for Business, Energy, and Regional Policy (MRNER) is the highest decision-making body within Nordic co-operation on regional policy. The Nordic ministers for regional affairs are part of a council of ministers together with the Nordic ministers for energy and business. Ministerial meetings are held once or twice a year.

The council of ministers decides on the strategic direction for co-operation on regional policy in the Nordic Region. The meeting between the Nordic ministers for regional affairs allows for interesting political discussions and serves as an arena for exchanging experience and developing new co-operations.

\section{Nordic Committee of Senior Officials for Regional Policy (EK-R)}

The Nordic Committee of Senior Officials for Regional Policy (EK-R) has content-based and administrative responsibility for the activities of the regional sector in close co-operation with the secretariat to the Nordic Council of Ministers. The chairmanship of EK-R rotates between the countries each year. The chairmanship is responsible for leading the work of the committee of senior officials. The committee of senior officials is a forum for exchanging knowledge and experience and for collegial discussions that help to create opportunities for policy development in the individual countries. EK-R monitors the implementation of the co-operation programme and is the recipient of the results of the activities carried out within the context of the programme.

\section{Secretariat to the Nordic Council of Ministers}

The secretariat to the Nordic Council of Ministers is tasked with supporting the Nordic countries' participation in cooperation on regional policy, primarily by providing administrative support to the chairmanship of co-operation on regional policy. In addition, the secretariat plays a special role in promoting cross-sectoral co-operation between the sectors of the Nordic Council of Ministers.

Nordregio - a Nordic knowledge hub on regional development

Nordregio shall provide a basis for the co-operation on regional policy of the Nordic Council of Ministers by supporting the Nordic Committee of Senior Officials 
for Regional Policy (EK-R) and the Nordic Council of Ministers for Business, Energy, and Regional Policy (MR-NER).

Nordregio will conduct research, offer advice, and communicate in the field of regional development, planning, and policy, thus contributing to the balanced and sustainable development of the Nordic Region, including the Arctic. Nordregio shall maintain and develop its role as a leading research institute in Europe in the field of regional studies, and shall continue to actively participate in European research programmes such as ESPON, Horizon 2020, and relevant Interreg programmes. Nordregio will provide data and perform territorial analyses at a pan-European level and conduct evaluations of the various national and European support programmes.

Nordregio shall serve as a Nordic research, advisory, and analysis institute with a focus on strategic, policy-relevant research for the relevant sectors of the NCM. In its role as advisor, knowledge broker, and Nordic knowledge bank for regional policy issues, Nordregio shall provide professional and effective support to the NCM and to national, local, and regional authorities. Nordregio shall maintain and further develop its statistical database with associated map descriptions, as well as the interactive map tool NordMap for analysing regional development in the Nordic Region.

Nordregio is a key stakeholder in the implementation of the co-operation programme and shall, in co-operation with EK-R and the thematic groups established for each focus area, plan and implement the activities required to realise the programme. Nordregio shall pass on knowledge and results from the implementation of the co-operation programme to relevant target groups through its information channels, as well as by way of participation in relevant national and regional networks and forums.

\section{Cross-border co-operation}

Co-operation between border regions and barriers to freedom of movement have long been a focus of Nordic co-operation. The Nordic countries have extensive experience of collaboration between nations and have worked actively to break down barriers to freedom of movement. In particular it is the far-reaching historical experience of co-operation in all border regions of the Nordic Region that has laid the foundation for looking at the Nordic Region as a pioneer in terms of cross-border cooperation in Europe. The Nordic countries' successful implementation of the Nordic Interreg programmes is a concrete example of this. The goal of the Nordic Council of Ministers' involvement in cooperation between border regions is to:

- Seize opportunities and overcome the barriers that national borders pose for functionally cohesive border regions.

- Promote development, innovation, and growth in the Nordic border regions.

Co-operation between border regions in the Nordic Region can be said to consist of 
two different elements that each contribute to the overall objectives:

- The cross-border co-operation committees that work in border regions between Denmark, Finland, Norway, and Sweden.

- The Nordic institution NORA (Nordic Atlantic Co-operation) that works in the Faroe Islands, Greenland, Iceland, Northern Norway, and Western Norway.

NORA and the cross-border co-operation committees work primarily to promote the competitiveness of business in the border regions, to identify and remove barriers to freedom of movement, to develop sustainable and climate-friendly energy and environment solutions, and to develop infrastructure and communications relevant to the border regions.

\section{The Cross-border co-operation committees} are membership organisations that pool local and regional stakeholders working to promote the development of Nordic border regions. The local and regional anchoring of co-operation is crucial and has helped to make the committees viable and to develop them further. The Nordic Council of Ministers is one of many sponsors of co-operation between border regions and the cross-border co-operation committees. The Nordic funds that currently help to finance the cross-border co-operation committees create an important platform for the activities.
The Nordic cross-border co-operation committees are, together with NORA, a vital part of Nordic co-operation between border regions, and the Nordic Council of Ministers for Business, Energy, and Regional Policy intends to continue its contribution to Nordic cross-border co-operation. In order to set in stone the objectives established by the Nordic Council of Ministers for co-operation between border regions, a Nordic border region strategy shall be drawn up within the context of the 2017-2020 co-operation programme. The strategy shall contribute to the development of the Nordic Council of Ministers' efforts in the border regions and clarify the cross-border co-operation committees' contribution to Nordic co-operation and the implementation of the co-operation programme. In light of the funding that the Nordic Council of Ministers for Business, Energy, and Regional Policy provides to the cross-border co-operation committees, an annual report on the cross-border co-operation committees' activities shall be submitted to the Nordic Committee of Senior Officials for Regional Policy. A clearer link between the cross-border co-operation committees' contribution to the sector's activities and the implementation of the co-operation programme can be developed and ensured within the context of a Nordic border region strategy. Within the context of this strategy, the forms of co-operation with the Nordic Committee of Senior Officials for Regional Policy should be clarified and ensured, along with follow-ups and reporting.

NORA is funded by the Nordic Council of Ministers and by a grant from the Nordic countries involved - the Faroe Islands, 
Greenland, Iceland, and Norway. NORA is active in the North Atlantic and the Arctic. NORA is guided by a strategic programme that has been in place from 2012 to 2016. Its activities develop North Atlantic and Arctic networks and projects within areas strategic to the region.

Within the context of the co-operation programme, a strategy for NORA will be drawn up. The strategy for the forthcoming period, 2017-2020, shall be based on the cooperation programme for regional policy and will clarify and specify NORA's role and contribution to its implementation. This subsequently reinforces the link between the direction of Nordic co-operation on regional policy and NORA. Within the context of this strategy, the forms of co-operation with the Nordic Committee of Senior Officials for Regional Policy should be clarified and developed, along with follow-ups, and reporting.

In addition, the Nordic Council of Ministers sees a need to continue to promote the systematic and continuous exchange of knowledge and experience between the Nordic cross-border co-operation committees, NORA, and Nordregio. The Nordic Committee of Senior Officials for Regional Policy and the secretariat to the Nordic Council of Ministers are expected to help make this possible.

\section{West Nordic Fund}

Within the context of the co-operation programme for regional policy 2013-2016, the Nordic Council of Ministers has implemented a review of the activities and organisation of the West Nordic Fund. The Nordic Council of
Ministers will continue to follow the activities of the West Nordic Fund, focusing on how the fund can support the development of the Faroe Islands and Greenland.

\section{A developed sectoral co-ordination of Nordic co-operation}

The challenges now faced by the Nordic Region require not only co-ordinated solutions and co-operation between the different levels of governance, but also sectoral coordination between policy areas that are of importance for regional development. If Nordic co-operation in the regional sector is to contribute to a Nordic advantage and reach the goals set out in the regional co-operation programme, expanded collaboration with other sectors with related assignments in Nordic co-operation is required.

The Nordic Committee of Senior Officials for Regional Policy, together with the secretariat to the Nordic Council of Ministers, is responsible for identifying and implementing cross-sectoral co-operation within the context of the co-operation programme. A couple of specific areas should be prioritised based on the focus areas of the co-operation programme, within which specific collaboration can be trialled and deepened. Examples include co-operation with the Nordic-Arctic co-operation programme, or expanded cooperation with the Nordic Committee of Senior Officials for Business in the area of green growth, and the Nordic Committee of Senior Officials for Fisheries and Aquaculture. Within the context of efforts relating to the supply of skills, co-operation with the Nordic Committee of Senior Officials for Labour may also be relevant. 

Nordic Council of Ministers

Ved Stranden 18

DK-1061 Copenhagen $\mathrm{K}$

www.norden.org

The Nordic ministers for regional affairs hereby present a joint Nordic co-operation programme that aims to lay the foundation for the evolved exchange of knowledge, to provide examples of successful initiatives within priority policy areas, and to strengthen joint efforts relating to regional policy in the Nordic Region.

Nordic co-operation on regional policy has a long history of creating good opportunities for learning, understanding, and joint action. This co-operation is based on the insight that joint learning and solutions are key to achieving results together that contribute to the sustainable development of the individual regions within the Nordic Region as a whole. 